\title{
O Futuro "Estatelante" da Documentação Administrativa
}

\author{
Benedicto Silva
}

\section{Introdução}

\section{$\mathrm{S}_{\mathrm{E}}$} E eu me curvasse, submisso, aos ditames da semântica, o Com efeito, o que se encontra nos estaleiros tecnológicos em matéria de documentação administrativa, já em fase operacional, ou ainda experimental, é tão avançado, ou tão nôvo, ou tão diferente, ou tão inusitado, que nenhuma outra expressão poderá descrever melhor do que esta: revolução documentalistica.

Alguém definiu o a que se chama revolução como «a inspiração exaltada da História». No caso presente, porém, o têrmo revolução seria empregado simplesmente para traduzir isto: mudança brusca, radical e atordoante.

A repulsa instintiva, que me provocam a pomposidade intelectual e o uso de títulos e rótulos demagógicos - suscetiveis de incutir a idéia de que o autor recorre a «iscas psicológicas ou ideológicas» para captar a atenção do leitor - levou-me a preferir o neologismo «estatelante», derivado aceitável do verbo estatelar (compare: exalar e exalante, relevar e relevante, ulular e ululante, falar e falante etc.), ao emprêgo de um título em que, por amor da clareza, se incluísse a palavra prestigiosa dos dias atuais - revolução. Registre-se, por exemplo, que os livros The Year 2.000, de Herman Kahn e Anthony J. Wiener, americanos, e Le Défi Américain, de Jean-Jacques Servan-Schreiber, francês, ambos best-sellers nos paises de origem e alhures, empregam calmamente o substantivo revolução e o adjetivo revolucionário para caracterizar o que está ocorrendo no campo da informação.

Os que lerem êste ensaio compreenderão, pois, que não haveria exagêro, nem impropriedade, em publicá-lo sob o título, por exemplo, de Revolução tecnológica na documentação administrativa.

Tolerada esta explicação preambular, venhamos ao assunto, como diria Joaquim Maria Machado de Assis. 


\section{O que é constante no passado é provável no futuro}

É bem conhecida a lei empirica,em que o homem se baseia, às vêzes até inconscientemente, para formular projeções e previsões. Enuncia-se a lei nos têrmos seguintes: «O que é constante no passado é provável no futuro».

A verificação das constâncias, com que qualquer fenômeno se apresente no passado, constitui base adequada para a previsão do seu comportamento no futuro.

Consideremos, por exemplo, o caso das sêcas periódicas, que flagelam as populações no Nordeste. Em virtude da constância com que têm ocorrido naquela região, através de decênios e séculos, e de seus efeitos calamitosos, as sêcas do Nordeste passaram a constituir problema público nacional. Em conseqüência, - Govếrno da República criou, primeiro, a Inspetoria de Obras contra as Sêcas, transformada, posteriormente, em Departamento Nacional de Obras Contra as Sêcas (1) e, mais tarde, a Superintendência do Desenvolvimento do Nordeste - SUDENE. (2).

Tal é o poder de convicção dessa lei empírica, que os constituintes incluiram, na Constituição de 1934 (3) e na de 1946 (4), disposições taxativas, determinando, a primeira, que o Govêrno da União despendesse «quantia nunca inferior a $4 \%$ », e a segunda, que destinasse pelo menos $3 \%$ de sua renda tributária, para «combater os efeitos da denominada sêca do Nordeste». Se a Constituição de 1946 não tivesse sido substituída pela de 1967, o referido mandamento constitucional vigoraria indefinidamente.

A razão por que os elaboradores das citadas Constituições inseriram aquêles dispositivos foi a evidência histórica da constância com que as sêcas periódicas se têm verificado na região. Essa constância no passado torna muito provável, quase certa embora não inelutável - a repetição do fenômeno no futuro.

É por meio da cbiservação das tendências dos fenômenos coletivos, especialmente dos fenômenos de massa, suscetíveis de mensuração e tratamento estatístico, que os governantes se habilitam a formular planos de trabalho, notadamente os de longa duração, e tomar medidas tendentes a controlar, ou retardar, ou acelerar em suma - modificar o comportamento dêsses fenômenos.

Não haverá talvez exagêro em dizer-se que a Futurologia, a chamada «Nova Ciência», se haja desenvolvido e esteja se desen-

(1) Lei $n^{\circ} 8.486$, de 28 de dezembro de 1945. Diário Oficial da União, de 2-1-1946 e 17-1-1946.

(2) Lei $\mathrm{n}^{0} 3.692$, de 15 de dezembro de 1959. Diário Oficial da União, de $6-12-1959$.

(3) Constituição do Brasil, 1934, Art. 177.

(4) Constitutção do Brasil, 1946, Art. 198. 
volvendo em conseqüência de aplicações, cada vez mais aperfeiçoadas e sofisticadas, da referida lei.

\section{Documentação e informação}

Quem se debruça sôbre as previsões que o mais famoso e discutido futurólogo do momento, Herman Kahn, diretor do misterioso Hudson Institute, faz sôbre as coisas que poderão acontecer nos próximos 31 anos, ou seja até à chegada do ano 2.000 , e toma conhecimento das informações e dados, em que êle se alicerça, para formular suas projeções, logo se convence de que o Nostradamus do Século XX está utilizando, em larga medida, o método de estudar as tendências constatadas no passado e projetá-las no futuro, por meio de extrapolações.

No que se refere particularmente à documentação e à informação, as «conjecturas sistemáticas» apresentadas pelo Diretor do Hudson Institute e seus colaboradores são, digamos assim, à mingua de melhor adjetivo, as mais «estatelantes» possiveis.

Com efeito, segundo as previsões de Herman Kahn e Anthony J. Wiener, os três fatôres que contribuirão mais fortemente, nos próximos 12 anos, para acelerar as mudanças que a Ciência e a Tecnologia estão provocando no mundo, são os seguintes: primeitro, a urbanização em grande escala, que está ocorrendo, com maior ou menor intensidade, em todos os países, especialmente nos Estados Unidos; segundo, a automação da indústria, já bastante desenvolvida, sobretudo nos Estados Unidos, embora as notícias a êsse respeito sejam um tanto exageradas; terceiro, a revolução da informação.

Quem diz informação automàticamente faz pensar em documentação. A associação semântica dêstes dois conceitos é espontânea e incoercivel. Cometeria o pecado de dar curso ao «óbvio ululante» quem afirmasse não ser possivel informação sistemática sem documentação organizada. A documentação é o lastro, a fonte, a medida, o contrôle e o repositório da informação.

\section{Inf̧ormação e Administração}

A utilização prevista e crescente de computadores eletrônicos no processamento de dados e informações prenuncia mudanças absolutamente revolucionárias na arte e ciência da Administração. Exemplo recente disso tem-se no efeito que os centros de processamento de dados fiscais produziram sôbre o contribuinte americano. Segundo fontes oficiais, a simples noticia de que o Ser-

(5) Kahn, Herman \& Wiener, Anthony J. The Year 2.000, McMillan Co., New York, 1967, p. 61-62, 91-98. 
viço das Rendas Internas dos Estados Unidos iniciara, primeiro em Atlanta. Capital do Estado de Georgia, e, depois, em Martinsburg, West Virginia, a 70 quilômetros de Washington, o escrutínio eletrônico das declarações do impôsto de renda determinou imediatamente aumento considerável da arrecadação respectiva.

Prevê-se para o futuro próximo que o risco de sonegar ou evadir impostos será tão grande nos Estados Unidos, que ninguém, nenhum contribuinte, por ingênuo que seja, tentará conscientemente enfrentá-lo. As informações sôbre as rendas auferidas por qualquer contribuinte e provenientes de tôdas as fontes possiveis, salários, dividendos, aluguéis, participação em lucro, juros, donativos etc., não importa se cada uma das rendas proceda de regiões ou Estados diferentes, acabarão por ser eletrônicamente identificadas e reunidas sob um número inconfundível, correspondente ao contribuinte e constante do cadastro fiscal.

\section{O ciclo da documentação}

A aplicação da automação no processamento da informação pode ser mais fàcilmente compreendida pelo público em geral, quando se analisam separadamente as distintas fases, sucessivas ou simultâneas, do ciclo da documentação.

Cabe advertir que o têrmo documentação enreda um verdadeiro feixe de sentidos. Afigura-se-me descabido, porém, examinar, neste ensaio exploratório, as diferentes definições propostas para o têrmo.

O ciclo da documentação abrange certo número de fases, ou etapas, das quais as mais importantes, salvo melhor juízo, são as seguintes: a reunião, o processamento, a armazenagem ou guarda, a recuperação e o uso. A reunião de documentos compreende, por sua vez, várias operações diferenciadas, como a aquisição a titulo oneroso, a aquisição a titulo gratuito, a permuta, a reprodução e o empréstimo. O processamento pode ser des crito por uma única palavra: indexação. $\left({ }^{\star}\right)$ A armazenagem ou guarda não necessita de explicação. A recuperação desdobra-se em busca, localização, apresentação ou reprodução pronta de determinado documento existente, ou apenas indexado, num centro de informações. O uso da informação também dispensa esclarecimento.

(*) Entende-se por indexação a arte de caracterizar determinado "item de informação" mediante o recurso de vincular a êle, "coerentemente", um ou mais têrmos. A palavra "têrmo" é empregada, aqui, no sentido mais lato e compreende qualquer forma de classe, subclasse, cabeçalho de assunto, palavra única ou combinação de palavras. (JoNker, Frederick. Indexing Theory. Indexing Methods and Search Devices, The Scarecrown Press, Inc. New York \& London. 1964, p. 20). 
No tópico intitulado Information Processing, do citado livro - The Year 2.000 - afirmam os autores que os problemas de automatizar completamente um acervo de documentos como o da Biblioteca do Congresso Americano, que compreende mais de 50 milhões de documentos, entre livros, revistas, relatórios, folhetos, partituras musicais, mapas, recortes etc., e colocar essa massa colossal de informações ao alcance instantâneo de qualquer pessoa, situada em qualquer parte do mundo, inclusive a bordo de uma nave interplanetária, depende de estudos que nos levem a compreender melhor e simular bem os meios pelos quais o ser humano faz associações de idéias e julgamentos de valor.

\section{Comparação e identificação de documentos}

Um ponto nevrálgico dêsse processo consiste na análise $e$ comparação de documentos.

A utilização do acervo de informações de qualquer entidade - biblioteca ou centro - geralmente se processa através das seguintes etapas: solicitação, busca, identificação, recuperação, apresentação do documento (no original ou em cópia) . Nas bibliotecas parcialmente mecanizadas, a busca da informação já se faz por meio de máquinas, naturalmente acionadas por alguém.

Por conseguinte, para que uma informação possa ser utilizada, pelo menos a solicitação e a busca, seja esta mecânica ou manual, exigem a intervenção humana.

Por enquanto, somente a mente humana comanda a faculdade de identificar os diferentes documentos que tratam de uma faixa comum de interêsse, analisar o conteúdo de cada um e identificar os assuntos ou tópicos específicos nêle contidos e os outros tópicos ou assuntos com os quais mantenham relações de afinidade.

A obtenção da informação torna-se mais fácil e menos onerosa quando o ciclo da documentação é dividido em etapas especializadas. Em primeiro lugar, cumpre determinar os limites do acervo no que diz respeito aos assuntos e objetivos. Em segundo lugar, o acervo de documentos - seja biblioteca, mapoteca, discoteca, hemeroteca ou arquivo de papéis administrativos, - deve ser processado, isto é, analisado, indexado e disposto com grande fidedignidade, ordem e precisão, a fim de habilitar os respectivos operadores a prever as solicitaçôes, se possivel a antecipá-las. $\mathrm{O}$ minimo que se exige dêles, no caso, é capacidade para atender aos pedidos de informação. Essa preparação pressupõe, em regra, um processo continuo e atualizado de indexação.

Em se tratando das bibliotecas tradicionais, sabemos que a tarefa da busca inicial compete ao usuário. Mediante manuseio dos catálogos, êste verifica a existência, ou não, do documento desejado e o solicita, oralmente ou por intermédio de um formulário. 
As conquistas tecnológicas, em particular o equipamento destinado às operações reprográficas e ao processamento automático de dados, quando aliadas aos computadores e aos novos meios de microfilmagem e microarquivamento, estão contribuindo para reduzir substancialmente o custo operacional dos grandes sistemas de armazenamento e recuperação de informações.

Até agora, porém, o trabalho humano exigido para reunir e analisar documentos ainda é considerável. Basta dizer que, de acôrdo com a experiência universal, do total do orçamento de uma biblioteca, 60 a $79 \%$ devem ser destinados ao pagamento do pessoal. Conseqüentemente, ficam apenas de 40 a $21 \%$ para a aquisição de livros, de equipamentos e serviços gerais.

\section{A documentação processada eletrônicamente}

Pelo que hoje se conhece em relação à lista de funções e atividades documentalísticas passiveis de computação, pràticamente o céu é o limite. O computador eletrônico já é capaz de indexar documentos, embora, por enquanto, utilize para isso sòmente as principais palavras dos respectivos títulos, e possa apenas selecionar palavras sinônimas para a indexação, dentro dos limites fixos do vocabulário ou thesaurus do próprio computador.

Aponta-se, como das mais prementes, a necessidade de aumentar a capacidade dos computadores para fazer associações de conceitos, de maneira que possam encarregar-se da busca e recuperação da literatura sôbre qualquer assunto que apresente muitas facêtas complementares ou subsidiárias.

Não estamos, neste momento, voltados para as perspectivas da documentação e da informação no ano 2.000 , mas, apenas, para o que acontecerá nesse campo até 1980 .

Confessam os autores do livro The Year 2000 a impossibilidade de predizer o progresso que se obterá, em matéria de computação da informação, no período que nos separa do ano 2000. Quais serão, então, as habilidades analiticas dos computadores? Serão êles capazes de desempenhar as funções mais complexas do documentalista, funções para çujo desempenho os sêres humanos atualmente dedicam decênios de estudo e experiência?

Por volta do ano 2000 , é provável que os computadores eletrônicos, já na décima geração, ou mesmo na décima quinta, sejam capazes de exercer, simular e até ultrapassar as faculdades intelectuais mais intrinsecamente «humanas», incluindo, talvez, até algumas de natureza estética e criativa, além de outras imprevisiveis, de que o homem não dispõe.

(6) RANDALL, G.E. Budgeting for a Company Library. In: $\rightarrow$ Special Libraries, $08 \cdot(3): 166-72$, March, 67.

(7) Kahn, Herman \& Wiener, Anthony J. Op. cit. p. 89. 
Os que chegarem lúcidos ao ano 2000 verão e verificarão e, se ainda lhes restar qualquer residuo de capacidade de surprêsa ante o inesperado e o inimaginável, ficarão boquiabertos, estatelados, «pálidos de espanto».

Em outras palavras, no ano 2000 , ou mesmo antes, êste mundo sublunar poderá estar às voltas com algo que jamais ocorreu a Júlio Verne, nem a H. G. Wells, nem a Aldous Huxley, a «inteligência artificial».

O computador poderá escrever odes e baladas, como Ovídio, Dante e Carlos Drummond de Andrade. O compuptador poderá compor sinfonias, como Mozart, Beethoven e Liszt. O computador escreverá novelas, como Flaubert, Balzac e Dostoievsky, O computador poderá escrever compêndios escolares. O computador poderá classificar os concorrentes dos concursos de beleza e dos festivais de música e de arte cinematográfica. O computador poderá traçar os planos governamentais. O computador poderá estabelecer a estratégia das campanhas politico-eleitorais, como, aliás, já fêz para os partidários da candidatura Richard Nixon nos Estados Unidos. O computador poderá prever o tempo. O computador poderá fazer tôda espécie de diagnóstico médico. O computador poderá prever até os acontecimentos mais inesperados, como o casamento de Jacqueline Kennedy com o bilionário greco-argentino Aristóteles Sócrates Onassis. O computador que não poderá fazer, então, a partir do ano 2020, por exemplo, o computador? Além de predizer o futuro de cada ser humano, será capaz de projetar as obras mais audaciosas, como o desvio de rios da bacia amazônica para o Pacífico, túneis através dos Andes, caminhos subterrâneos entre Moscou e Paris, ou entre Roma e Cairo etc. etc. etc.

Em matéria de documentação e informação administrativa, os governos só não saberão o que não quiserem.

\section{Barateamento da informação eletrônica}

Cumpre lembrar que estamos focalizando o mais complexo problema da organização, armazenamento e recuperação de informação. Para o caso, porém, das bibliotecas ou centros de informações especializados, cujos contornos podem ser descritos mais simplesmente e, destarte, compreendidos de maneira clara pelos leigos, já existem sistemas muito avançados de documentação, e que continuarão a ser aperfeiçoados ràpidamente.

(8) Minsky, Marvin L. Artificial Intelligence. In: - Information (a Scientific American Book), W. H. Freeman and Co., S. Francisco, 1966, p. $193-210$. 
Em artigo publicado na edição de Scientific American, setembro de 1966, sob o titulo Information Storage and Retrieval, BenAmi Lipetz diz o seguinte (9):

«Já existem e são utilizados sistemas completamente automáticos aptos a detetar códigos indexados de vários tipos (bobinas de película ótica, cartão de película, cartão magnético, cartão de cartolina etc.), para recuperar, reproduzir e apresentar documentos».

E mais adiante: «em relação a numerosos propósitos, já se pode eliminar totalmente o intermédio do homem, graças a dois recursos diferentes.

Em primeiro lugar, o teor de documentos e registros pode ser ràpidamente transmitido, cada vez a custo mais reduzido, por dispositivos automáticos. Tratandose de registros ou documentos cujo teor já se encontre em condições de ser lido por máquinas, a transmissão pode ser fàcilmente feita, ao longo de linhas ou fios telefônicos, ou por canais de microondas, a aparelhos reprodutores ou gravadores, assim como a computadores. Tratando-se de registros ou documentos não legiveis por máquina, o teor pode ser rebuscado e esquadrinhado por dispositivos óptico-eletrônicos e em seguida transmitidos e reconstituídos na extremidade receptora, por reprodutores de fac simile, ou por telas de televisão.

Em segundo lugar, a capacidade de controlar o processo da transmissão ou mesmo de intervir nêle por interação pode ser exercida, na extremidade receptora, tanto pelo homem, quanto pela máquina. Conseqüentemente, o interessado pode fazer uso de um computador, ou empregar ùnicamente a interceptação, mesmo que se encontre em ponto remoto do local de transmissão. Devido a êstes dispositivos, as barreiras geográficas dos repositórios e sistemas de recuperação de informação começam a desaparecer. Estão surgindo, em seu lugar, várias rêdes de dispositivos apropriados de comunicação, ligando os usuários da informação com numerosas e imbricadas coleções de documentos.

Cumpre observar, entretanto, que os custos de transmissão de dados ainda são relativamente altos, o que impede, por enquanto, que o desaparecimento dos sistemas tradicionais se transforme num-processo revolucionário galopante». (10)

Com efeito, Herman Kahn e Anthony Wiener opinam que, lentro de 15 anos, aproximadamente, os custos de transmissão

(9) LIPETZ, Ben-Ami, Information Storage and Retrieval. In: - Information (a Scientific American Book), W. H. Freeman and Co., S. Francisco, 1966, p. 188.

$\therefore$ (10) Op. cit., loc. cit. p. 190. 
de dados e informações por meios automáticos, qualquer que seja a distância entre o transmissor $\mathrm{e} o$ receptor, provàvelmente estarão reduzidos de tal maneira, que o armazenamento e a recuperação de informações se tornarão «um processo revolucionário galopante» .

\section{A centralização da documentação - A distopia horripilante de George Orwell : 1984}

Encontrava-se em debate no Congresso Americano, em 1962, proposta para a criação de um Centro Nacional de Dados, no qual os arquivos de cêrca de 20 ou mais organizações governamentais seriam reunidos em um lugar. Trata-se de uma operação gigantesca de centralização fisica dos arquivos, apontada como exemplo do que está emergindo nos horizontes da documentação administrativa. No caso em aprêço, não está prevista a fusão de todos os arquivos num sistema único, mas sòmente a sua reunião em um só local, conservados, porém, os arquivos individuais, a fim de que a busca e a recuperação da informação seja tão facilitada e útil quanto possivel. A centralização física dos arquivos, no caso, deve contribuir para aumentar a segurança das instalações e a proteção dos documentos contra certas ameaças potenciais, como incêndio, inundação, umidade, roubo, insetos, ratos etc. As instalações podem ser projetadas e executadas de tal modo que se tornem invulneráveis a qualquer dêsses inimigos tradicionais dos arquivos.

Em futuro mais remoto, entre o ano 1980 e o ano 2000, será possivel a existência de arquivos únicos ou centros nacionais de informações, que contenham, em relação a cada habitante do país, dados completos e atualizados sôbre as caracterísitcas biológicas e juridico-sociais, assim como sôbre os tributos a que esteja sujeito, a situação legal, os antecedentes, a atuação relativamente à segurança nacional, a ficha médica, a carreira profissional, os empregos ocupados, o crédito bancário, e assim por diante.

É evidente que a existência de tais centros precipitará o advento da situação apocaliptica descrita por George Orwell em sua distopia científica, 1984. Isto implica em supressão total da vida privada. $\mathrm{O}$ cidadão poderá ser conhecido, vigiado, regulamentado. regimentado, devassado, enquadrado de tal maneira, que as próprias inclinações e até os pensamentos de cada um serão objeto de inquisição governamental, ou de qualquer instituição, ou de outro indivíduo, por meio de dispositivos eletrônicos.

Não resta dúvida que, quando a computação eletrônica da documentação permitir reunir, identificar e fornecer, em frações de minutos, todos os dados relativos a todos os habitantes de uma sociedade politicamente organizada, esta se encontrará em cheio

(11) KAHN, Herman \& WIENER, Anthony J. Op. cit., p. 96. 
no mundo distópico imaginado por George Orwell, a menos que a religião, ou o restabelecimento de padrões éticos, transforme a sociedade em seio de Abraão, e os dirigentes, detentores do poder político, em virtuosos e fraternais varões de Plutarco.

A documentação que por êsses avanços tecnológicos poderá ser reunida, mantida e atualizada em centros administrados e controlados pelo poder público e, conseqüentemente, accessíveis às autoridades policiais, fiscais e outras, provocará, sem dúvida alguma, tremendas e imprevisiveis mudanças nas relações entre governantes e governados.

\section{A direção da «nau do Estado» como se fôsse um automóvel}

No que diz respeito ao planejamento governamental, a posse imediata de dados atualizadíssimos e a verificação diária de suas variações poderão habilitar o govêrno a dirigir a nau do Estado - para nos valer desta sediça imagem literária - exatamente como hoje um comandante acompanha o curso de seu navio, ou um pilôto dirige seu avião, ou um chofer dirige seu automóvel, isto é, captando instantâneamente as condições circunstantes, os obstáculos imprevistos, as alterações de última hora e, conseqüentemente, fazendo no momento oportuno as manobras necessárias para evitar desastres ou prejuizos, ou resultados indesejáveis.

É intuitivo, por outro lado, que a coleta, organização e arquivamento de minuciosos dados pessoais, sociais, econômicos e biológicos contribuirão de maneira extraordinária para o progresso da Economia, da Sociologia, da Medicina, da Educação, assim como para facilitar as tarefas dos agentes públicos - os policiais, os inspetores, as autoridades fiscais, os sanitaristas etc.

As técnicas disponiveis, aliás, bastam para habilitar os órgãos interessados a processar as informações existentes e descobrir muitas espécies de correlações sutis, assim como as relações de causa e efeito, coisa que está acontecendo e continuará a aperfeiçoar-se. em consonância com o progresso da arte de processamento de dados.

A acumulação de experiências em matéria de direção, manipulação e desenvolvimento de novas técnicas e teorias provocará naturalmente, como subprodutos, progressos expressivos na compreensão e contrôle de vários aspectos da sociedade.

Dado o progresso científico até agora conquistado e o ritmo de velocidade com que se amplia, é previsivel que em futuro próximo um chefe de Estado - um General de Gaulle, um Primeiro Ministro Wilson, um Presidente Nixon, um Primeiro Ministro Kossyguine - poderá fàcilmente ter sob o comando e o contrôle dos dedos sistemas de aparelhos de televisão conjugados, exibindo, ao mesmo tempo, aspectos diferentes de algo anormal, como 
o desenvolvimento de uma guerra, ou das várias frentes de uma batalha, ou de violências de rua, ou desordens coletivas que estejam ocorrendo em diferentes partes do pais, ou do mundo.

Tendo que examinar sucessivamente muitas telas, será necessário um sistema de contrôle remoto, que permita ao observador passar de uma a outra, ir adiante e voltar atrás, quase simultâneamente, a fim de colhêr, confirmar ou retificar uma impressão direta, viva, flagrante, dos acontecimentos em marcha.

Isso impõe o aproveitamento de espaço. De modo geral, as câmaras de televisão tenderão a ser muito pequenas e utilizadas sòmente para efeito de ampla vigilância preventiva. Em momentos de crise, porém, deverão ser de dimensões imensas, para proporcionar a visão e o exame de detalhes.

A faculdade de acompanhar, em flagrante, através da televisão, o que esteja acontecendo em vários lugares de um país, ou do mundo, ao mesmo tempo, provàvelmente será extensiva às próprias estações emissoras, e até mesmo ao público diretamente. Herman Kahn e Anthony Wiener predizem que essa conquista tecnológica será uma espécie de benefício contingenciado. Òbviamente, tal capacidade poderá incutir uma falsa impressão psicológica de conhecimento e percepção das condições e ocorrências. locais, diferentes do que realmente esteja acontecendo, o que tenderia a dar lugar a medidas excessivas de contrôle centralizado. A centralização do contrôle, combinada com a descentralização da execução, constitui um dos princípios mais sãos das ciências da Administração. Nem por isso, uma centralização excessiva de contrôle deixa de constituir problema para os detentores do poder, especialmente para os que têm a seu cargo a responsabilidade de funções executivas.

\section{A informação instantânea e o cumprimento da lei}

Como já ficou subentendido, a documentação administrativa do futuro imediato exercerá, similarmente, influência extraordinária nas atividades policiais. O govêrno do Estado de New York por exemplo, recorrendo ao auxílio de computadores, tem realizado experiências para fazer recair sôbre motoristas faltosos o rigor das leis do trânsito. Como o acesso à cidade de New York se faz através de pontes e túneis de grande extensão, que ligam a Ilha de Manhattan a Long Island e aos Estados limítrofes, a policia identifica as placas dos automóveis que entram nas pontes ou túneis em direção a Manhattan e, enquanto êstes seguem seu caminho, manda verificar, por meio de computadores, a situação de cada veículo no arquivo das infrações das leis do trânsito.

(12) KahN, Herman \& Wiener, Anthony J. Op. cit., p. 97.

(13) Kahn, Herman \& Wiener, Anthony J. Op. cit., loc. cit. 
Graças a êsse ardil tecnológico, a polícia tem conseguido realizar o aparente milagre de descobrir e prender numerosos motoristas, - para grande surprêsa dos mesmos, - antes que cheguem ao fim da ponte ou do túnel.

Ora, sistemas similares a êste podem ser completamente automatizados. Na verdade, não haverá dificuldade alguma em reproduzir as placas dos automóveis por meio de um alfabeto adequado incutido na memória magnética de um computador. Em seguida, as placas serão projetadas em uma câmara de televisão colocada num separador automático. É mais do que provável que os pontos de cobrança de pedágio, ou outros pontos estratégicos das rodovias, receberão e utilizarão êsse equipamento ou equipamento semelhante em futuro próximo.

Isso não concorreria apenas para a detecção de violações das leis de trânsito e prisão de motoristas faltosos, mas, tamb'ém, para indicar a intensidade do tráfego, num sentido ou noutro, e ainda para facilitar outras investigações.

A documentação administrativa que os governos nacionais, estaduais ou provinciais e municipais poderão reunir, armazenar e atualizar com o auxílio dos equipamentos modernos, notadamente dos computadores eletrônicos, os habilitará a ouvir e gravar, temporária ou permanentemente, conversas telefônicas.

Grupos de freqüentadores de bares, restaurantes, boites e outros recintos poderão ser fàcilmente vigiados por computadores de alta velocidade, que alertarão as autoridades sempre que, no meio das conversações, surjam certas palavras chaves - possivelmente indicadoras de situações suspeitas.

\section{A seleção de pessoal para os serviços do Estado}

Já nos referimos ao grau de precisão que o planejamento das atividades governamentais poderá adquirir em futuro próximo, talvez mesmo em nossos dias, graças aos modernos meios de captação, tratamento e transmissão da informação.

Como o órgão responsável por êste Seminário é o DASP, vamos desenvolver algumas considerações sôbre os efeitos que a documentação administrativa, tal como entrevista ao longo desta palestra, projetará sôbre a administração de pessoal. Nada diremos quanto à perfectibilidade dos assentamentos de pessoal pertencente ao serviço público. Ater-nos-emos apenas ao problema nevrálgico da seleção. Utilizando os métodos tradicionais do concurso de provas e de títulos, ou de ambos, a seleção de pessoal é um processo lento, complicado e oneroso, porque envolve relações, nem sempre amistosas, com clientelas diferenciadas, dispersas geogràficamente, mal informadas, muitos de cujos membros não raro se rebelam contra os resultados dos concursos. 
Que poderá oferecer o progresso tecnológico e o desenvolvimento da Psicologia aplicada, para tornar a seleção de pessoal mais simples, mais rápida e mais barata? Para responder a esta pergunta e terminar minha palestra, citarei uma passagem da Introdução que descrevi, em 1964, para o livro de Beatriz Wahrlich, Administração de Pessoal - Principios e Técnicas.

Diz o seguinte:

«Seleção eletrônica.Prevejo, também, que na sociedade do futuro haverá estabelecimentos centrais complicadissimos, verdadeiros labirintos de células eletrônicas, para armazenar informações sôbre as qualidades pessoais, as aptidões e habilitações de todos os habitantes em idade émpregável. Serão como que agências centrais de coiocação.

Quando qualquer entidade, pública ou particular, necessitar de um porteiro, de um entomólogo, de um cosmonauta, de um atuário ou de uma costureira, terá apenas que pedir à agência central eletrônica de pessoal os dados dos três ou cinco melhores candidatos disponiveis no momento. Um minuto depois poderá escolher, dentre êles, o que mais convier. Poderá solicitar, também, os dados de tôdas as pessoas vivas, empregadas ou não, que possuam os requisitos desejados e tentar atrair, mediante ofertas irresistiveis de emprêgo, a que os possuir em maior grau.

Aliás, a verificação prévia, rotineira, fria, do potencial de serviço de cada indivíduo virá oferecer a vantagem de ser mais objetiva, mais isenta, do que a que se faz sob' a pressão de necessidades existentes de pessoal para colocação imediata.

Já há os «bancos de informações», eletrônicamente acionados, que memorizam milhões e milhões de dados sôbre indivíduos, entidades ou acontecimentos, dados que são instantâneamente trazidos ao consciente dos monstros eletrônicos, isto é, às fitas sôbre as quais os teclados de suas máquinas automáticas imprimem as respostas que lhes são pedidas. O que estou imaginando é, pois, uma aplicação especializada, de que já se conhecem amostras, da universalização e automatização do processo de recrutamento e exame para fins de emprêgo.

Esta previsão não é mais do que uma extrapolação das tendências atuais de racionalização do trabalho em todos os setores da atividade humana, juntamente com uma visão antecipada da utilização de computadores ele-

(14) Wahrlich, Beatriz. Administração de Pessoal - Principios e Técnicas, Fundação Getúlio Vargas, Rio, 1964, Introdução. 
trônicos para armazenar, em suas memórias ilimitadas, os dados individuais e aferidos por laboratórios de Psicologia».

\section{Conclusão}

O propósito desta palestra não poderia ser outro senão o de entremostrar, em linhas gerais, por meio de ilustrações pertinentes, o papel que o progresso tecnológico começa a desempenhar no processamento da documentação administrativa. Tudo indica que a arte e ciência da Administração receberão contingentes formidáveis de recursos informativos, precisos, amplos e atualizados, com os quais será mais fácil para os governantes e seus assessôres identificar e medir as tendências e prevenir, por meio de medidas tempestivas, pràticamente tôdas as modalidades de desajustamentos sociais.

Benedicto Silva - Diretor do Instituto de Documentação, da Fundação - Getúlio Vargas. 